\title{
La cultura argentina hoy. ¡Tendencias!
}

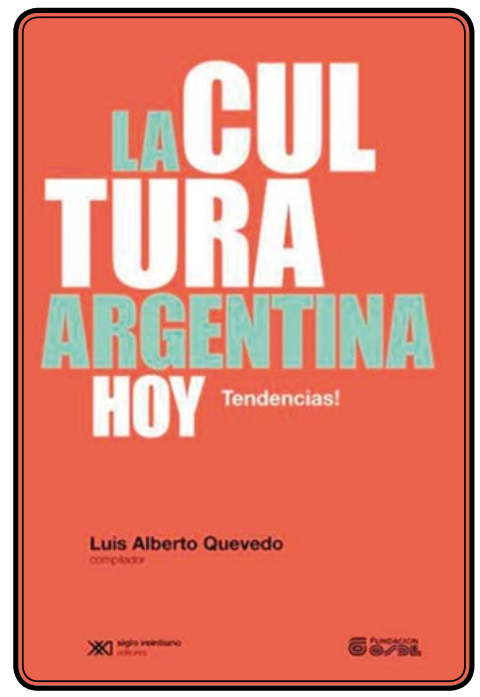

Luis Alberto Quevedo (coordinador). 2016. La cultura argentina hoy. ¡Tendencias! Buenos Aires: Siglo XXI editores.

En los últimos años el territorio de la cultura se ha ensanchado, entrecruzado y complejizado, $\mathrm{y}$ hemos perdido definitivamente sus bordes. Las discusiones respecto de qué es la cultura conocen memorables batallas en la literatura especializada. Sin embargo, esas batallas resultarían simples escaramuzas si tuviéramos más certezas respecto de la diversidad a la que nos enfrentamos hoy. Lo cierto es que este libro no se propone saldar debates académicos, sino indagar en los mundos de vida de quienes transitan los pliegues de la cultura contemporánea.

Nuestro camino consiste en mostrar algunas transformaciones producidas en las percepciones, creencias, representaciones y prácticas culturales de la sociedad argentina. La intención es "ambiguar" y no desambiguar, volver complejo un territorio y no ordenarlo, desencajar nuestras ideas y no reafirmarlas.

Emprendimos esta travesía con un grupo de autores que desde la academia o desde las instituciones de la cultura trabajan los diversos temas aquí tratados y que aceptaron pensar desde la perspectiva de las tendencias; o sea, pensar dónde estamos e imaginar hacia dónde vamos. Por eso, no es un libro académico, ni de estado de la cuestión de cada uno de los campos que se abordan: es más bien un libro de ensayos, de experimentación.

Las hibridaciones han sido características de la cultura a lo largo del tiempo y en muchas direcciones. Para limitarnos sólo a la más significativa, mencionemos que las personas y los colectivos se apropian de las políticas, de las industrias culturales y de lo que producen los medios y los integran a sus prácticas, muchas veces de modos distintos a los que fueron pensados. En el mismo sentido y con signo inverso, los medios, las industrias culturales y el Estado se apropian de las prácticas que funcionan por fuera del mercado y las procesan en nuevos formatos. En estas negociaciones, idas y vueltas del sentido, se forjan muchas de nuestras prácticas, consumos e imaginarios culturales. 
La cultura está en permanente mutación, y por eso intentamos tomar lo que, a nuestro juicio, son núcleos de condensación de los fenómenos de época. Estos núcleos se relacionan con la apropiación del espacio público, con las formas de producir/consumir desde los medios y las tecnologías, con los usos del cuerpo y de las prácticas sexuales, con las identidades, con las formas en que incorporamos alimentos, marcas, tecnologías, signos, imaginarios y usos.

Para jugar un poco con el intertexto, proponemos aquí algunas "Instrucciones de lectura".

Considere que este libro nació de la idea de indagar sobre las nuevas tendencias en el campo de la cultura argentina. Tome esta presentación y el primer capítulo como un GPS (deberíamos decir "carta de navegación", es más elegante, pero quizás un poco extemporáneo para un libro que no pretende orientar "recorridos fijos"). Sepa que aquí procuramos no pensar la cultura paradigmáticamente. No se trata de resumir novedades (de manera monográfica) de las artes plásticas, la fotografía o el cine, la literatura o la música y de una larga lista de etcéteras que usted podrá completar casi sin esfuerzo. E incluso, en su mayoría, estas cuestiones no están siquiera tratadas; pero cuando aparecen, lo hacen de una manera endiabladamente revuelta y entramada (palabra muy apreciada en estos tiempos) con otros fenómenos: las intervenciones sobre (y en) el cuerpo, la apropiación del espacio público, los imaginarios acerca de las tecnologías, las formas del amor.

Tenga en vista los análisis transversales, porque en esa línea está el texto. Podemos agregar a los ejes recién nombrados los modos de leer, las nuevas militancias, la fragmentación y la diversidad, la crisis del canon y de las figuras de autoridad. Recuerde también que la intención explícita del texto es mirar el campo cultural de otro modo, al sesgo, como decía Antonio Machado ("Da doble luz a tu verso, / para leído de frente / y al sesgo") y abrir así los campos de la mirada, volverla estrábica, provocar ideas nuevas y lecturas desacostumbradas.

Por último, algunos reconocimientos necesarios. Quiero agradecer muy especialmente a todos los colegas que han escrito en este libro. Y no sólo porque todas sus contribuciones son originales, agudas y minuciosas, pensadas para este proyecto, sino porque cada uno ha sido generoso con sus ideas: todos los autores han leído y debatido los distintos capítulos, y encontramos en ellos marcas de las escrituras de los otros. Hay citas entrecruzadas, temas que se intersecan, autores que todos hemos leído (aunque a cada uno nos hayan dejado señales diferentes).

Agradezco también a todos los amigos de la Fundación OSDE, porque creyeron en este proyecto, porque me alentaron siempre a llevarlo adelante, porque lo sostuvieron y sobre todo porque se involucraron en él desde un comienzo. Gracias especialmente a Tomás Sánchez de Bustamante, Omar Bagnoli, Florencia Badaracco y María Isabel Menéndez, que leyeron este libro desde sus primeras versiones y lo disfrutaron y aprendieron tanto como yo. Y gracias también a Luciano Padilla López, quien trabajó incansablemente para que esta edición tuviera el cuidado que se merece.

Y por supuesto a mis dos amores: a ellas dedico este libro.
Luis Alberto Quevedo Septiembre de 2015 


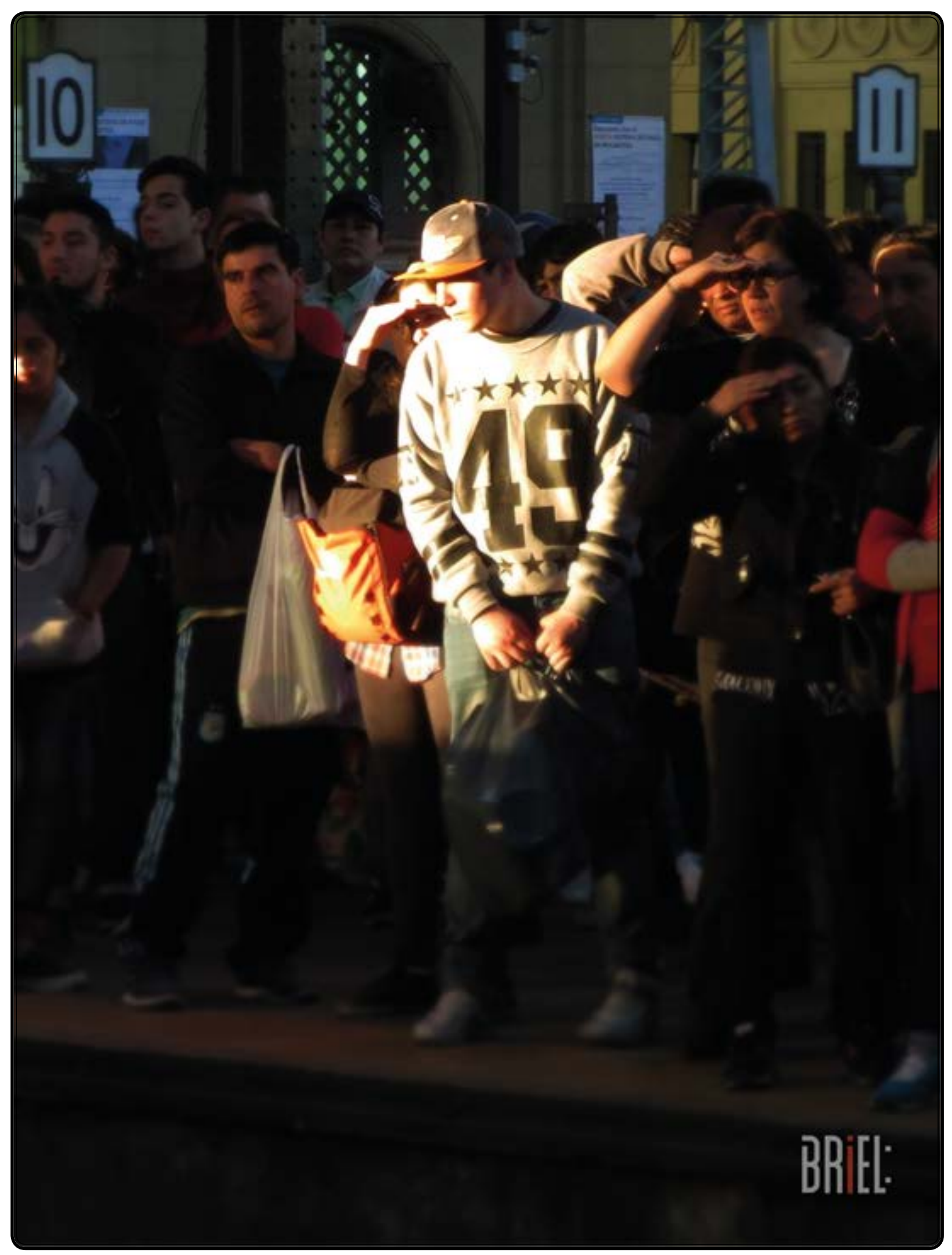

Laburar la resistencia. 
